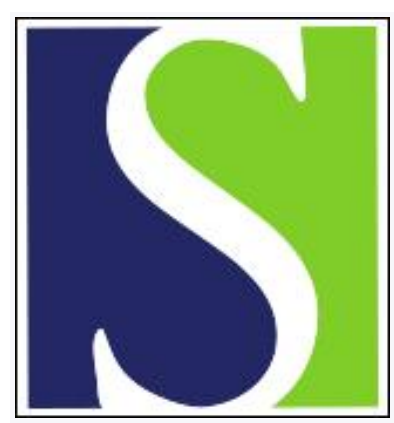

Scand J Work Environ Health 1986;12(4):237-241

https://doi.org/10.5271/sjweh.2145

Issue date: Aug 1986

Pathophysiological and hygienic aspects of hand-arm vibration.

by Pyykko I, Starck J

This article in PubMed: www.ncbi.nlm.nih.gov/pubmed/3775307

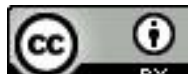




\title{
Pathophysiological and hygienic aspects of hand-arm vibration
}

\author{
by Ilmari Pyykkö, MD, Jukka Starck, PhD ${ }^{1}$
}

\begin{abstract}
PYYKKÖ I, STARCK J. Pathophysiological and hygienic aspects of hand-arm vibration. Scand $J$ Work Environ Health 12 (1986) 237-241. A review of current knowledge on the pathophysiological and hygienic aspects of the hand-arm vibration syndrome is given. Hemodynamic measurements indicate that the primary factor in vibration-induced white finger is an increase in the peripheral resistance of finger circulation that is present after local and general cooling. The reason for this increase is not known, but it is postulated that an excessive affinity of vasoactive substances for the efferent receptors exists, this affinity being potentiated during local cooling of the digits. So far, the hygienic rating of hazardous vibration in individual work phases is of limited value in diagnosing possible cases, but this rating does provide guidelines for general risk assessment. A consideration of several factors, eg, intermittency of the work, duration of daily exposure, impact of vibration, individual physiological responses, climate, etc, might improve the accuracy of the rating, but the influence of these factors on the development of the vibration syndrome is still poorly understood. Of various preventive measures, only those that significantly reduce vibration will be beneficial in the long run.
\end{abstract}

Key terms: etiology of vibration disease, hemodynamic aspects, measures for preventing vibration, rating of vibration, vibration syndrome.

The hand-arm vibration syndrome is composed of symptoms arising from finger circulation, the peripheral nerves, and the musculoskeletal system of the upper limbs (40). The vascular symptoms appear in Raynaud's phenomenon, in which the circulation of the fingers is periodically interrupted when exposed to the cold. The affection of the peripheral nerves causes paresthesias of the hands and arms, especially during the night, and forces workers to shake and rub their hands. The symptoms arising from the musculoskeletal system appear, for example, in grip force as excessive muscle fatigue.

Even though bone cysts, decalcification, and arthrosis of the bones in the hands and arms have been linked to hand-arm vibration in some occupations (22, $26,27,55)$, a lack of such a connection in other occupations $(20,21,24)$ indicates that the appearance of possible bone and joint degeneration as a result of exposure to vibration is not generally accepted. Thus, further evidence is needed. According to several reports hand-arm vibration may also induce dysfunction in the central autonomic nervous system $(3,5,31,32)$. However there has hitherto been no conclusive data supporting the occurrence of such an effect as the result of exposure to hand-arm vibration $(16,17)$.

The diagnostic work-up for the vibration syndrome is still a matter of controversy $(40,41,57)$. The most carefully devised procedures have been tests detecting

\footnotetext{
Institute of Occupational Health, Helsinki, Finland.
}

Reprint requests to: Dr I Pyykkö, Institute of Occupational Health, Topeliuksenkatu 41 a A, SF-00250 Helsinki, Finland. the retarded circulation that leads to vibration-induced white finger (VWF) $(8,34,54)$. A cold provocation test in which the finger is locally cooled during an arrest of finger circulation can reveal about $70 \%$ of the cases of VWF; but this test has a somewhat low sensitivity $(36,41,57)$. In the testing for peripheral nerve symptoms, a retarded sensory nerve conduction velocity, an enhanced vibrotactile detection threshold, or a deprived two-point discrimination has been considered an objective sign of peripheral neuropathy; but these findings occur at a variable success rate $(9,29,48)$. The psychophysical grip force test is not very suitable for evaluating excessive muscle fatigue in the vibration syndrome in individual cases $(11,12)$. So far much of the diagnostic work has been based on careful histories on the exposure and on the latency and characteristics of the symptoms. In the vibration syndrome, a complete history may sometimes be difficult to obtain due to socioeconomic factors or the physical strain of the work $(16,40)$.

Thus, so far, at least 15 different limits have been proposed for the general risk assessment of vibration (19). The ratio between the highest and lowest limit is about 10. Better agreement seems to exist for vibration acceleration. The discrepancies existing between some basic evaluations, such as those of the dose-response relationship, illustrate the need for further studies of hand-arm vibration. Digital high-speed measuring techniques and computer-based data processing may allow for new understanding in the evaluation of factors determining the hazardousness of hand-arm vibration (37).

The aim of this paper is to review the pathophysiological and hygienic aspects of hand-arm vibration. 


\section{Etiologic aspects of the vibration syndrome}

Although the nature of the vibration syndrome is well known, a satisfactory explanation of its etiology is still lacking. Treatment and prevention have thus far been focused on the alleviation of the symptoms.

Lewis was the first to present the hypothesis that VWF is caused by nerve ending defects that lead to excessive vasoconstriction when the vessel wall is exposed to cold (28). Extending this theory. Magos \& Okos (30) not only showed that the vessels reacted more strongly to locally applied cold but that coldinduced vasodilation was lost. This excessive response was explained as the result of the accumulation of vasoactive substances that cannot be metabolized by the affected vessels. Challenging this theory, Hellström \& Lange Andersen (21) showed a normal degree of coldinduced vasodilation in subjects with VWF.

Interestingly, Azuma et al (7) have recently shown, both in vivo and in vitro, that the smooth muscles of vessel walls exposed to vibration respond more strongly to noradrenaline than do unexposed muscles. Similar vascular hyperresponsiveness to noradrenaline, as shown by Azuma et al (7), has also been observed by Folkow et al $(13,14)$ in cases in which the muscular layer of the arterioles and the arteriovenous shunts was increased. If the fault is in the receptors, then normal vasoconstrictor nervous tone can lead to increased peripheral resistance in subjects with VWF through the strong contraction of the arterioles and arteriovenous shunts. If excessive, this contraction, in conjunction with decreased blood flow, can finally lead to the collapse of the vessel wall and an attack of VWF.

The hyperreactivity of the vessels of subjects with VWF does not seem to be limited to locally applied cold stimulus. Cold, noise, and vibratory stimuli also reflexively induce an enhanced vasoconstriction in the affected vessels $(31,32,39)$. It has been proposed that enhanced peripheral vasoconstriction may be produced by faulty local factors in combination with enhanced vasoconstrictor nerve tone. The central output of the sympathetic nervous system enhances responses of the local vasoconstrictor mechanisms. Such a situation generally occurs in outdoor workers when the body and the vessels of the finger are cooled simultaneously.

A reduction of systolic blood pressure in the digital arteries during local finger cooling under suprasystolic pressure has been demonstrated as occurring in VWF $(4,34)$. During local cooling an increase in venous tone has also been observed $(18,42)$. Both these factors contribute to the increase in the peripheral resistance and reduction of finger blood flow. A part of the prominent increase in peripheral resistance in subjects with VWF undoubtedly occurs due to central sympathetic output (15). Nevertheless, a pathologically high peripheral resistance during cold persisted after blockage of the sympathetic nerves to the finger, a phenomenon indicating that local factors play an important role in the genesis of VWF (18).
Pyykkö et al (44) found no evidence that the myogenic tone of vasomotor oscillation in VWF patients differs from that of healthy volunteers. Therefore, increased local vasoconstrictor responses to cold are probably not of myogenic origin in subjects with VWF. It is more likely that the fault in VWF might be in the coupling between the nerve and smooth muscle of the vessel at the adrenergic repector (7) or, less likely, in the wall : lumen ratio at the arteriolar level $(6,52)$.

So far the exact mechanism by which vibration induces a possible fault in the mechanisms controlling vessel tone remain to be elucidated. There is support for the theory that in VWF the fault may be local, in the finger vessels, but the nature and the exact mechanisms of the "excessive vasospasm" remain to be explained before any conclusions can be drawn.

\section{Hemodynamic aspects of vibration-induced white finger}

Digital blood flow is directly related to the pressure difference in the finger and inversely related to peripheral resistance. The peripheral resistance is dependent on an individual constant $(k)$, the length of the capillary bed $(i)$, the viscosity of the blood $(\mu)$, and the radius of the lumen of the vessel $(r)$ as described in the formula

$$
R=(8 \times k \times l \times \mu) / r^{4} .
$$

Although local mechanisms operating on the vessel wall of the resistance arterioles and capillary beds may contribute to vasoconstriction (56), in normal subjects the outflow of the sympathetic vasoconstrictor nerves is far more important. This outflow is aimed at the resistance arterioles, precapillary sphincters, and arteriovenous anatomosis (1). A slight decrease in the radius causes a powerful increase in the peripheral resistance and results in a reduction in the flow, provided that the pressure is not changed. Thus, under normal conditions, changes in the radius of the vessel lumen provides an efficient control of skin circulation. Any adverse changes in the factors determining peripheral resistance have an impact on the outcome of and susceptibility to VWF.

From the hemodynamic point of view, cooling accompanied by compression of the finger skin reduces the patency and length of the finger vessels and results in an increase in peripheral resistance, which may secondarily lead to a reduction in the blood flow in VWF. In recent experiments Pyykkö et al (42) and Gemne et al (18) recorded finger systolic blood pressure, finger maximal arterial inflow, and finger venous opening pressure during local cooling. The results showed, in fact, that in subjects with VWF the arterial inflow was limited as the result of high peripheral resistance. An abnormally high peripheral resistance in VWF is believed to be caused by a fault in the adrenergic receptors controlling skin circulation. The affinity of transmitter substances for receptors is temperature dependent. 
Local exposure to cold affects the alpha-adrenergic receptors and promotes the vasoconstriction induced by the sympathetic nervous system through two different mechanisms, ie, a reduction of the degradation of transmittor substances and the sensitization of the affinity of alpha-adrenergic repectors for transmittor substances (56). The slowing of the degradation of transmittor substances is achieved by the inhibition of neuronal uptake, by delayed enzymatic degradation, and by retarded diffusion of noradrenaline (25).

In some studies, it has been shown that persons with VWF have a higher viscosity of the circulatory blood than those without VWF (35). Since blood viscosity also influences peripheral resistance, it seems likely that those subjects with a high or pathological viscosity of the blood tend to be selected into the group with VWF and that the high or pathological viscosity condition is not caused by hand-arm vibration.

Structural changes have also been found in workers exposed to vibration $(6,52)$. Intimal thickening and hypertrophy of the medial layer are the most characteristic findings. Since these factors affect the lumen of the digital arteries and reduce the radius of the vessels, they increase peripheral resistance.

Substitution of subcutaneous tissue with callosities during prolonged vibration (51) reduces the size of the capillary bed and the apparent length of the vascular bed, and also augments peripheral resistance. An increase in general sympathetic tone, induced either by emotional tension or by drugs such as nicotine, also favors the outbreak of symptoms (38).

\section{Technique for measuring risk}

Although the technical measurement and analysis of the vibration signal is well established, the evaluation of important factors in risk assessments has been less understood. Thus, so far, measuring devices and methods have not been refined even to the level existing for noise measurements.

The variables which are known or believed to affect the severity of occupational exposure to hand-arm vibration can be divided into three groups - physical, biodynamic, and individual (49). Nevertheless, monitoring each worker for all the variables included in all three groups is impractical. It is necessary to reduce the number of variables to manageable proportions. The guidelines of the International Organization for Standardization (ISO) defines those variables whose effects should be specified as follows (23):

\footnotetext{
Level of vibration

weighted/unweighted

intermittency

rest periods

daily dose

total dose

Frequency of vibration
}

\author{
frequency range \\ bandwidth \\ weighting \\ Associated variables \\ direction combinations \\ grip and push forces \\ tool weight \\ temperature
}

The aim of the guidelines should be to present preferred ranges of the variables and their combinations. If all exposures were constant in intensity and in a single frequency in one direction, it might be sufficient merely to specify the respective responses. The variables for different tools could then be simply weighted to achieve an equivalent weighted level to be further used for the comparison of different exposures and tools in relation to the symptoms of the vibration syndrome. In practice, however, most exposures to handarm vibration are intermittent and vary in intensity and frequency during each exposure period. Therefore a standard for the measurement and assessment of vibration exposure should specify methods for averaging different levels, frequencies, directions, and durations of vibration exposure. The result of averaging could provide a single number or a measure for vibration during the workday, and eventually also over a complete period of different exposures. The ultimate result would then be that the measurement of vibration could be conducted with averaging and weighting techniques. The vibration standard should specify how this averaging and weighting should be performed.

\section{Preventive measures}

Different devices have been developed for the damping of vibration, eg, protective (absorbing) gloves, rubber and spring insulators, balanced engines, etc ( 10 , 33). When tested, protective gloves did not reduce the level of vibration but did interfere with work safety $(33,53)$. Experience with the insulation of the front handle of the chain saw in combination with a reduced level of vibration has been promising and probably explains the recent decrease of vibration syndrome among forest workers $(45,46,47)$. The linear response of the hand-arm system to the acceleration level of vibration (43) indicates that it is important to produce tools in which vibration is inhibited, eg, tools with balanced engines. Technical measures to decrease workers' exposure to vibration should also be more widely applied in several other occupations, not only in forestry work.

Teisinger (53) has proposed that the method of operation determines whether or not a worker using a vibrating tool will become disabled by VWF. New, unskilled workers tightly grip the tool and therefore allow high levels of vibration to be transmitted to their hands; older, more skilled workers support the vibrating 
device lightly. Recent examinations (11) confirmed the connection between an excessive hand grip force of forest workers during chain sawing and VWF.

Since a heavy tool demands a strong grip, the upper limit for the weight of vibrating tools has been set at $10 \mathrm{~kg}$ in some vibration standards (the Soviet standards from 1971 and the Czechoslovakian hygienic norms from 1969). In tests with different grip forces, we were able to confirm that an increase in muscular force of, eg, $12 \mathrm{~dB}$, increased the vibration in the hand-arm system by $4 \mathrm{~dB}$ (43).

Although the vibration emitted from a tool is in inverse proportion to the weight, it is proportional to the power (33). If the weight of the tool is decreased but the power remains the same, the intensity of the vibration increases. Care must, therefore, be taken to insure that, when the weight of a tool is decreased, the vibration level is also reduced.

It seems, on the basis of physiological experiments and available data, that vibration at very low frequencies is not as harmful as vibration at higher frequencies $(2,39,43)$. Decreasing the dominant frequency of vibrating tools would also probably reduce the prevalence of vibration disorders.

\section{Aspects for future consideration}

A comparison of different limits, either proposed or actually used for the general risk assessment of vibration exposure, shows that most of them indicate that high frequencies above $1200 \mathrm{~Hz}$ are not as hazardous as lower frequencies. The different proposed limits are very similar, since most standards and proposals are based on the same data and assumptions. However, although high-frequency components are neglected, some studies have proposed that these components should also be taken into account in measurements of vibration. Moreover limits in frequency ranges also neglect the variations in time history and the impulse of the signal $(49,50)$. Epidemiologic studies are needed which would quantify high-frequency and impulse vibration for risk assessment purposes.

Vibration measurements are usually taken from the handle of the tool. However, grip or push forces and the weight of the hand-arm system may decrease vibration in the handle and increase the transmission of the vibration to the hand (43). This occurrence may lead to hygienic underestimations of vibration since the transmission and hazardousness of vibration have increased. Further research should be aimed at the development of the model, and artificial hand-arm system, necessary for laboratory measurements.

The definition, symptoms, and evaluation of the vibration syndrome have not yet been defined to the degree that they could be widely accepted. The diagnostic criteria for vibration syndrome are not standardized, and the relationship between hazardous vibration and the symptoms of vibration syndrome varies according to the criteria used for the evaluation. A more solid basis for establishing norms limiting hazardous vibration is needed. Probably the only symptom of the vibration syndrome that can be objectively used in the evaluation of a dose-response effect is the presence of VWF.

\section{References}

1. Abrahams DI. Circulation in the extremities. Academic Press Inc. New York, NY 1967.

2. Agate JN, Druett HA. A study of portable vibrating tools in relation to the clinical effect which they produce. Br J Ind Med 4 (1947) 141-163.

3. Andreeva-Galanina ET, Karpova NI. On degeneration and regeneration of peripheral nerves under the effect of experimental vibration [in Russian]. Gig Tr Prof Zabol 13 (1969): 2, 4-7 (English abstract).

4. Arneklo-Nobin B. The white cold hand. University of Lund, Lund 1983. (Doctoral dissertation).

5. Asanova TP. Vibration disease among workers using portable power tools in Finnish shipyards. In: Korhonen $O$, ed. Vibration and work: Proceedings of the Finnish-Soviet-Scandinavian vibration symposium. Helsinki, March 10-13, 1975. Institute of Occupational Health, Helsinki 1976, pp 52-62.

6. Ashe WF, Cook WT, Old JW. Raynaud's phenomenon of occupational origin. Arch Environ Health 5 (1962) $333-343$.

7. Azuma T, Ohhashi T, Sakaguchi M. Vibration-induced hyperresponsiveness of arterial smooth muscle to noradrenaline with special reference to Raynaud's phenomenon in vibration disease. Cardiovasc Res 12 (1978) $758-764$.

8. Bovenzi M, Petronio L, Di Mario F. Epidemiological survey of shipyard workers exposed to hand-arm vibration. Int Arch Occup Environ Health 46 (1980) $251-266$.

9. Brammer AJ, Taylor W, Piercy J. Assessing the severity of the neurological component of the hand-arm vibration syndrome. Scand J Work Environ Health. 12 (1986) 428-431.

10. Dieckman D. Ein mechanisches Model für das schwingungserregte Hand-Arm-System des Meschen. Int $Z$ Angew Physiol 17 (1958) 125-132.

11. Färkkilä M, Pyykkö I, Korhonen O, Starck J. Hand grip forces during chain saw operation and vibration induced white finger in lumberjacks. Br J Ind Med 36 (1979) 336-341.

12. Färkkilä M, Pyykkö I, Korhonen O, Starck J. Vibrationinduced decrease in the muscle force in lumberjacks. Eur J Appl Physiol 43 (1980) 1-9.

13. Folkow B, Hallbäck M, Lundgren $Y$, Weiss L. Background of increased flow resistance and vascular reactivity in spontaneously hypertensive rats. Acta Physiol Scand 80 (1970) 93-106.

14. Folkow T, Hallbäck M, Weiss L. Cardiovascular responses to acute mental "stress" in spontaneously hypertensive rats (SHR). Acta Physiol Scand 84 (1972) $7-8 \mathrm{~A}$.

15. Futatsuka M, Pyykkö I, Färkkilä $M$, Korhonen $O$, Starck J. Blood pressure, flow and peripheral resistance of digital arteries in vibration syndrome. $\mathrm{Br} \mathrm{J}$ Ind Med 40 (1983) 434-44I.

16. Gemne G. "Vibration disease" as a central nervous disorder - Development, symptomatology, and pathophysiology of Soviet and Japanese classifications. J Low Freq Noise Vibration 1 (1983): special issue, 19-35.

17. Gemne G. Autonomic integration of external and internal stimuli, and the Soviet concept of "diencephalic syndrome'”. J Low Freq Noise Vibration 1 (1983): special issue, $63-68$. 
18. Gemne G, Pyykkö I, Starck J, Ilmarinen R. Circulatory reaction to heat and cold in the vibration-induced white finger with and without sympathetic blockade. - An experimental study. Scand J Work Environ Health 12 (1986) 371-377.

19. Griffin MJ. Hand-arm vibration standards and doseeffect relationship. In: Brammer AJ, Taylor W, ed. Vibration effects on the hand and arm in industry. John Wiley \& Sons, New York, NY 1982, pp 259-268.

20. Härkönen $H$, Riihimäki $H$, Tola $S$, Mattsson $T$, Pekkarinen M, Zitting A, Husman K. Symptoms of vibration syndrome and radiographic findings in the wrists of lumberjacks. Br J Ind Med 41 (1984) 133-136.

21. Hellstróm B, Lange Andersen K. Vibration injuries in Norwegian forest workers. Br J Ind Med 29 (1972) 255-263.

22. Horváth F, Kákosy T. Asetische Nekrosen an Handwurzelknochen von Motorsägearbeitern. Z Orthop 111 (1973) 906-913.

23. International Organization for Standardization. Guidelines for the measurement and the assessment of human exposure to hand-transmitted vibration. Second draft. Geneva 1984. (ISO/DIS 5349.2-1984).

24. James PB, Yates JR, Pearson JG. An investigation of the prevalence of bone cysts in hands exposed to vibration. In: Taylor W, Plemear PL, ed. Vibration white finger in industry. Academic Press, London 1975, pp $43-51$.

25. Janssens WJ, Vanhoutte PM. Effect of cooling on efflux of $\left({ }^{3} \mathrm{H}\right)$-noradrenalin in canine cutaneous veins. $J$ Pharmacol 66 (1979) 148.

26. Kumlin T, Wiikeri M, Sumari P. Radiological changes in carpal and metacarpal bones and phalanges caused by chain saw vibration. Br J Ind Med 30 (1973) 71-73.

27. Laitinen $J$, Puranen $\mathbf{J}$, Vuorinen $\mathbf{P}$. Vibration syndrome in lumbermen (working with chain saws). J Occup Med 8 (1974) 552-556.

28. Lewis T. Vascular disorders of the limbs. Second edition. MacMillan, London 1949.

29. Lucas E. Peripheral nervous system and hand arm vibration. In: Brammer AJ, Taylor W, ed. Vibration effects on the hand and arm in industry. John Wiley \& Sons, New York, NY 1982, pp 39-43.

30. Magos L, Okos G. Cold dilatation and Raynaud's phenomenon. Arch Environ Health 7 (1963) 402-410.

31. Matoba T, Chiba M, Toshima T. Cardiovascular features of vibration syndrome: An adaptive response. In: Brammer AJ, Taylor W, ed. Vibration effects on the hand and arm in industry. John Wiley \& Sons, New York, NY 1982, pp 25-30.

32. Matsumoto K, Itoh N, Kasamatsu T, Iwata H. A study on subjective symptoms based on total operating time of chain saw. Jpn J Ind Health 191 (1977) 22-28.

33. Näslund $U$. Design problems in the reduction of vibration in chain saws. In: Taylor W, ed. The vibration syndrome. Academic Press, London 1974, pp 61-70.

34. Nielsen SL, Lassen NA. Measurement of digital blood pressure after local cooling. J Appl Physiol 43 (1977) 907-910.

35. Okada A, Yamashita T, Nagopno C, Ikeda T, Yachi A, Shibata S. Studies on the diagnostic and pathogenesis of Raynaud's phenomenon of occupational origin. $\mathrm{Br}$ $\mathrm{J}$ Ind Med 28 (1971) 353-357.

36. Olsen N, Nielsen SL. Diagnosis of Raynaud's phenomenon in quarrymen's traumatic vasospastic disease. Scand J Work Environ Health 5 (1979) 249-256.

37. Pekkarinen J, Starck J. Digital high-speed sampling of combined exposure to noise and vibration. Scand J Work Environ Health. 12 (1986) 327-331.
38. Pyykkö I. The prevalence and symptoms of traumatic vasospastic disease among lumberjacks in Finland. Work Environ Health 11 (1974) 118-131.

39. Pyykkö I. A physiological study of the vasoconstrictor reflex in traumatic vasospastic disease. Work Environ Health 11 (1974) 170-186.

40. Pyykkö I. Clinical aspects of hand-arm vibration syndrome. Scand J Work Environ Health (in press).

41. Pyykkö I, Färkkilä M, Korhonen O, Starck J, Jäntti V. Cold provocation tests in the evaluation of vibrationinduced white finger. Scand J Work Environ Health 12 (1986) 254-258.

42. Pyykkö I, Kolari P, Färkkilä M, Starck J, Korhonen O, Jäntti V. Finger peripheral resistance during local cooling in vasospastic disease. Scand J Work Environ Health 12 (1986) 395-399.

43. Pyykkö I, Färkkilä M, Toivanen J, Korhonen O, Hyvärinen $J$. Transmission of vibration in the hand-arm system with special reference to changes in compression force and acceleration. Scand J Work Environ Health 2 (1976) 87-95.

44. Pyykkö I, Gemne G, Kolari P, Starck J, Ilmarinen R, Aalto $\mathrm{H}$. Vasomotor oscillation in vibration-induced white finger. Scand J Work Environ Health 12 (1986) 389-394.

45. Pyykkö I, Korhonen O, Färkkilä M, Starck J, Aatola A. A longitudinal study of vibration syndrome among Finnish forest workers. In: Brammer AJ, Taylor W, ed. Vibration effect on the hand and arm in industry. John Wiley \& Sons, New York, NY 1982, pp 157-167.

46. Pyykkö I, Korhoner O, Färkkilä M, Starck J, Aatola $\mathrm{S}$. Vibration syndrome among Finnish forest workers, a follow-up from 1972 to 1983 . Scand J Work Environ Health 12 (1986) 307-312.

47. Pyykkö I, Sairanen E, Korhonen O, Färkkilä M, Hyvärinen $\mathrm{J}$. A decrease in the prevalence and severity of vibration-induced white fingers among lumberjacks in Finland. Scand J Work Environ Health 4 (1978) 246-254.

48. Seppäläinen A-M. Peripheral neuropathy in forest workers: A field study. Work Environ Health 9 (1972) 106-111.

49. Starck J. Characteristics of vibration hand grip force and hearing loss in vibration syndrome. University of Kuopio, Kuopio (Finland) 1984. (Original reports 4/1984, natural sciences)

50. Starck J, Pyykkö I. Impulsiveness of vibration as an additional factor in the hazards associated with handarm vibration. Scand J Work Environ Health 12 (1986) 323-326.

51. Steawart AM, Goda DF. Vibration syndrome. Br J Ind Med 27 (1979) 19-27.

52. Takeuchi T, Imanishi J. Histopathological observations in finger biopsy from thirty patients with Raynaud's phenomenon of occupational origin. J Kumamoto Med Soc 58 (1984) 54-70.

53. Teisinger J. Vascular disease disorders resulting from vibrating tools. J Occup Med 14 (1972) 129-133.

54. Thulesius O, Brubaker A, Berlin E. Response of digital blood pressure to cold provocation in cases with Raynaud's phenomenon. Angiologia 32 (1981) 113-118.

55. Vainio $\mathrm{K}$. Om vibrations syndrome, särskilt hos maskinborrare. Nord Hyg Tidskr 31 (1950) 249-265.

56. Vanhoutte PM, Janssens WJ. Thermosensitivity of cutaneous vessels and Raynaud's disease. Am Heart J 100 (1980) 263-265.

57. Voss $\mathrm{P}$, Olsen $\mathrm{N}$, Nielsen SL. Vibrationsskader fra håndvärketöjer. Lydteknik, Teknologisk Institut, Tåstrup (Denmark) 1979 (Hovedrapport). 